\title{
Cloning of CDP-Diacylglycerol Synthase from a Human Neuronal Cell Line
}

\author{
Anne M. Heacock, Michael D. Uhler, and Bernard W. Agranoff \\ Neuroscience Laboratory, University of Michigan, Ann Arbor, Michigan, U.S.A.
}

\begin{abstract}
A critical step in the supply of substrate for the phosphoinositide signal transduction pathway is the formation of the liponucleotide intermediate, CDP-diacylglycerol, catalyzed by CDP-diacylglycerol synthase. Further insight into the regulation of phosphoinositide biosynthesis was sought by cloning of the gene for the vertebrate enzyme. Sequence of the corresponding gene from Drosophila was used to prepare a probe for screening of a human neuronal cell cDNA library. A cDNA was isolated with a predicted open reading frame of 1,332 bases, encoding a protein of $51 \mathrm{kDa}$. The amino acid sequence showed $50 \%$ identity ( $75 \%$ similarity) to that of Drosophila eye CDP-diacylglycerol synthase and substantial similarity to the Saccharomyces cerevisiae and Escherichia coli homologues. Northern blot analysis, with human cDNA riboprobes, suggested that the corresponding mRNA was expressed in all human tissues examined. Expression of the human cDNA in COS cells resulted in a more than fourfold increase in CDP-diacylglycerol synthase activity. Knowledge of the sequence of vertebrate CDP-diacylglycerol synthase should facilitate further investigations into its regulation and the possible existence of distinct isoforms. Key Words: Phosphoinositides-Inositol lipids-Signal transduction

J. Neurochem. 67, 2200-2203 (1996).
\end{abstract}

The phosphoinositide signal transduction pathway plays a major role in cell-cell communication within the CNS (Fisher et al., 1992). Although many aspects of this second messenger system have been investigated in great detail, comparatively little is known regarding the regulation of the availability of its phospholipid substrate, phosphatidylinositol (PI) 4,5-bisphosphate ( $\left.\mathrm{PIP}_{2}\right)$. Prolonged stimulation of phospholipase $\mathrm{C}$ may result in depletion not only of $\mathrm{PIP}_{2}$, but also of PI. The continued operation of this pathway would require resynthesis of PI from its liponucleotide precursor, CDP-diacylglycerol (CDP-DAG) (Agranoff et al., 1958 ). The very low tissue levels of the CDP-DAG (Thompson and MacDonald, 1976) suggest that the reaction catalyzed by its biosynthetic enzyme, CDP-DAG synthase (CDS), may be rate-limiting for phosphoinositide synthesis and thus may be a potential site of regulation. Such a regulatory role is supported by the finding that mutations in a photoreceptor-specific isoform of CDS in Drosophila resulted in light-dependent retinal degeneration (Wu et al., 1995 ). Conversely, overexpression of eye CDS gave rise to an amplification of the light response. The results of the Drosophila study also indicate that discrete CDS isoforms may subserve specific cellular functions, for example, signal transduction versus other metabolic needs of the cell. In eukaryotic cells, CDP-DAG is a precursor not only of the phosphoinositides but also of the mitochondrial phosphatidylglycerols, including cardiolipin. A dual localization of CDS in both mitochondrial and microsomal fractions has been documented (Kent, 1995), and evidence indicating the existence of distinct isoforms of CDS in these compartments has been reported (Mok et al., 1992).

The cDNAs encoding the enzyme have been cloned from Escherichia coli (Icho et al., 1985) and Saccharomyces cerevisiae (Shen et al., 1996), in addition to Drosophila (Wu et al., 1995). Further progress in understanding the role played by CDS in regulation of neuronal signal transduction requires the cloning and characterization of a vertebrate CDS. Here we describe the cloning, sequencing, and expression of a cDNA encoding a human neuronal CDS. A preliminary report of this study has appeared in abstract form (Heacock et al., 1996).

\section{MATERIALS AND METHODS}

\section{Cloning and sequencing}

A fragment corresponding to nucleotide residues 66-172 of a 194-bp human pancreas cDNA sequence (GenBank accession no. T11364) was amplified by PCR from human pancreas cDNA (Clontech) and then subcloned into pGEM$\mathrm{T}$ (Promega) and sequenced. The cDNA fragment was then labeled with $\left[\alpha-{ }^{32} \mathrm{P}\right] \mathrm{dATP}$ by random priming and used to screen a human NT2 (uninduced) neuronal cell library (ZAP Express; Stratagene). Screening of $9 \times 10^{5}$ phages yielded five positive clones ( $c d s l-5$ ), four of $2.3 \mathrm{~kb}$ and one of 2.1 $\mathrm{kb}$, which were plaque-purified using standard techniques. Following in vivo excision of the pBK-cytomegalovirus (CMV) phagemids, nucleotide sequencing of the inserts was

\footnotetext{
Resubmitted manuscript received July 22, 1996; accepted July 30, 1996.

Address correspondence and reprint requests to Dr. A. M. Heacock at Neuroscience Laboratory, University of Michigan, 1103 East Huron Street, Ann Arbor, MI 48104-1687, U.S.A.

Abbreviations used: CDP-DAG, CDP-diacylglycerol; CDS, CDPdiacylglycerol synthase; CMV, cytomegalovirus; PI, phosphatidylinositol; $\mathrm{PIP}_{2}$, phosphatidylinositol 4,5-bisphosphate; SDS, sodium dodecyl sulfate.
} 
performed by the dideoxy chain termination method with either Sequenase or Taq DNA polymerase (Amersham) and targeted oligonucleotide primers. Sequence analysis was accomplished using the University of Wisconsin Genetics Computer Group software package.

\section{Transfection of COS cells}

COS cells were transiently transfected by a calcium phosphate precipitation method with a modified version of the $c d s-5$ pBK-CMV plasmid. Because the 5'-untranslated region of $c d s-5$ contained a stop codon, this region was deleted together with the vector sequence downstream of the NheI site adjacent to the CMV promoter, up to and including the EcoRI multiple cloning site. A Kozak sequence (Kozak, 1991) was created at the ATG initiation codon, and a His $6^{-}$ tag sequence was inserted immediately $3^{\prime}$, to increase efficiency of translation and allow purification by $\mathrm{Ni}^{2+}$ affinity chromatography, respectively. Control COS cells were transfected with the unmodified $c d s-5$ plasmid, which in preliminary experiments was found not to result in any change in CDS activity. Transfection efficiency, determined by cotransfection with a $\beta$-galactosidase-CMV vector, averaged $20-30 \%$.

\section{Assay of CDS}

Transfected cells were harvested after $48 \mathrm{~h}$ and then sonicated in $50 \mathrm{~m} M$ Tris-maleate buffer ( $\mathrm{pH} \mathrm{6.5)}$ ), containing 1 $\mathrm{m} M$ phenylmethylsulfonyl fluoride. Assay tubes contained $1 \mathrm{~m} M$ phosphatidic acid (egg; Sigma), $1 \mathrm{~m} M\left[\alpha^{-32} \mathrm{P}\right] \mathrm{CTP}$ $\left(2.2 \times 10^{4} \mathrm{dpm} / \mathrm{nmol}\right), 1 \mathrm{mg} / \mathrm{ml}$ bovine serum albumin, 10
FIG. 1. Comparison of amino acid sequence of human NT2 cell CDS with Drosophila, Saccharomyces cerevisiae (yeast), and Escherichia coli sequences. Identical residues are shaded in gray. Numbers on the left refer to positions in the human sequence. Alignments were carried out using the Gap program.

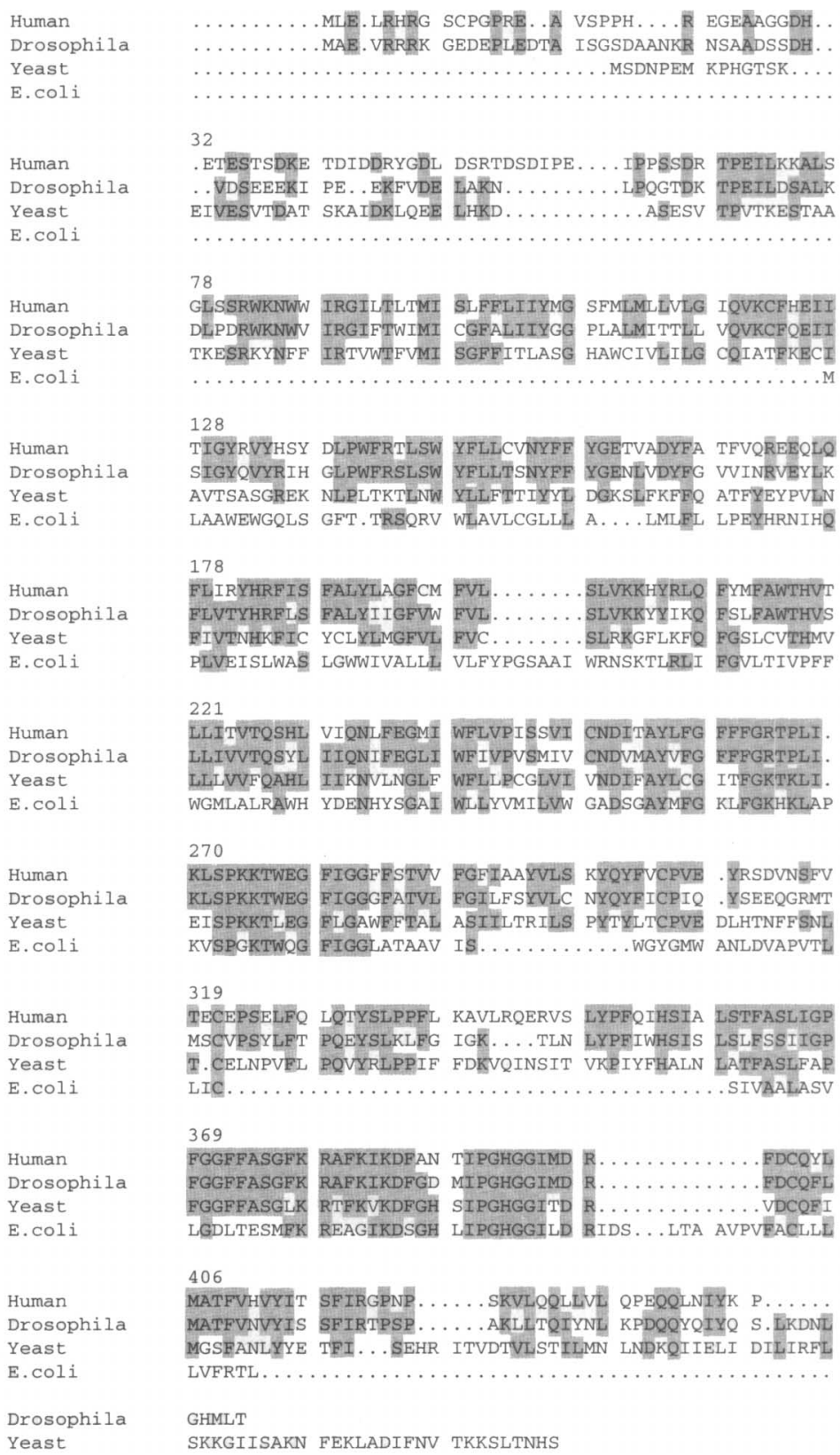


$\mathrm{mg} / \mathrm{ml}$ azolectin (soybean phosphatidylcholine; Sigma), 20 $\mathrm{mM} \mathrm{MgCl}$, and $30-40 \mu \mathrm{g}$ of cellular protein in a final volume of $200 \mu \mathrm{l}$ (modified from the procedure of Sparrow and Raetz, 1985; Kelley and Carman, 1987). Reactions were stopped after 6 or $8 \mathrm{~min}$ by addition of $1.7 \mathrm{ml}$ chloroform/ methanol ( $1: 2 \mathrm{vol} / \mathrm{vol}$ ), lipids were acid-extracted (Fisher and Agranoff, 1980), and radioactivity in 1.0-ml aliquots of the organic phase was determined. Data are expressed as mean \pm SEM values. Statistical significance was assessed by Student's $t$ test.

Protein concentration was determined by the method of Bradford (1976).

\section{Northern analysis}

A human multi-tissue northern blot, containing $\sim 2 \mu \mathrm{g}$ of poly $(\mathrm{A})^{+}$RNA per lane, was purchased from Clontech. For riboprobe synthesis, either a 725-bp Pst I-BamHI restriction fragment (containing 553 bases of the C-terminal coding region) or a 360-bp EcoRI-Pst $\mathrm{I}$ restriction fragment of $c d s$ 5 was inserted into a pGEM-T vector (Promega). The resulting plasmid was digested with HindIII or EcoRI, respectively, followed by labeling with $\left[\alpha-{ }^{32} \mathrm{P}\right] \mathrm{UTP}$ in the presence of T7 RNA polymerase. Blots were hybridized overnight at $60^{\circ} \mathrm{C}$ in a solution containing $400 \mathrm{mM}$ sodium phosphate buffer ( $\mathrm{pH} 7.2$ ), $1 \mathrm{~m} M$ EDTA, 5\% sodium dodecyl sulfate (SDS), $1 \mathrm{mg} / \mathrm{ml}$ bovine serum albumin, and $50 \%$ formamide, then washed in $15 \mathrm{~m} M \mathrm{NaCl}, 1.5 \mathrm{~m} M$ sodium citrate, and $0.1 \%$ SDS at $65^{\circ} \mathrm{C}$, and exposed to Kodak XAR5 film.

\section{RESULTS AND DISCUSSION}

Comparison of the sequence of Drosophila CDS with the data base of expressed sequence tags revealed a matching partial cDNA sequence from human pancreas. This fragment was amplified by PCR and used to screen a human NT2 neuronal cell cDNA library. Of the five positive clones isolated, the four 2.3-kb clones had identical restriction digest patterns. Partial sequencing of the $2.1-\mathrm{kb}$ clone indicated that it was closely related to the larger clones and that two deletions, one of $111 \mathrm{bp}$ in the 5 '-untranslated region and one of $117 \mathrm{bp}$ in the C-terminal coding region, accounted for the smaller size. The latter deletion did not disrupt the reading frame, but it remains to be determined if the $2.1-\mathrm{kb}$ clone encodes a functional protein. One of the $2.3-\mathrm{kb}$ clones, $c d s-5$, was completely sequenced on both strands. It contained a predicted open reading frame of 1,332 bases, preceded by stop codons in all three reading frames, encoding a protein of 444 amino acids with a molecular mass of 51,486 Da. The 3 '-untranslated region did not contain a potential polyadenylation signal, indicating that although it contains the entire coding region, $c d s-5$ is a partial cDNA, probably derived from the binding of the oligo(dT) primer to an internal A-rich region rather than to the poly $(\mathrm{A})$ tail. The amino acid sequence of the presumptive human enzyme is highly homologous to Drosophila CDS ( $50 \%$ identity, $75 \%$ similarity) and shares 37 and $31 \%$ identity with the S. cerevisiae and $E$. coli homologues, respectively (Fig. 1). Greater homologies were observed in regions that were highly conserved, particularly in the C-terminal sequence.

Hydrophobicity analysis of the human enzyme (Kyte and Doolittle, 1982) indicated three putative membrane spanning domains, consistent with the membrane localization of the protein. All three eukaryotic enzymes contain a hydrophilic $\mathrm{N}$-terminal region that is lacking in the $E$. coli enzyme. The

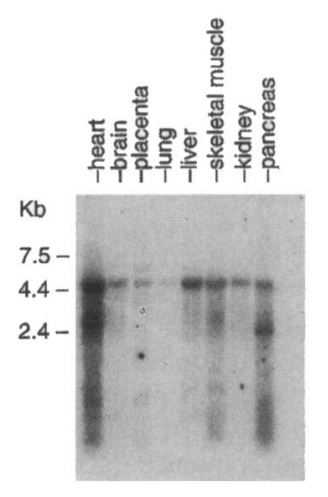

FIG. 2. The tissue distribution of CDS mRNA in human tissues was analyzed by northern blotting as described in Materials and Methods. The 725-bp Pstl-BamHI probe was used. Positions of RNA molecular weight markers are indicated.

latter is only one-half the size of its eukaryotic homologues, suggesting that the $\mathrm{N}$-terminal and $\mathrm{C}$-terminal extensions found in the eukaryotic enzymes are not required for catalytic activity and may subserve other functions such as organelle targeting or regulation. No potential mitochondrial or endoplasmic reticulum targeting sequences were found in the human cDNA. Of note are cysteine residues conserved among the eukaryotic enzymes, at positions 306, 321, and 402 of the human sequence, with the latter two also shared by the $E$. coli enzyme. The activity of the yeast enzyme is reported to be sensitive to sulfhydryl inhibitors (Kelley and Carman, 1987), as was the human enzyme. Treatment of sonicated human neuroblastoma cells (SH-SY5Y) with 5 $\mathrm{m} M N$-ethylmaleimide or $100 \mu M p$-chloromercuriphenylsulfonic acid resulted in 86 and $96 \%$ inhibition of CDS activity, respectively. In contrast, $N$-ethylmaleimide did not inhibit the E. coli CDS (Langley and Kennedy, 1978).

Confirmation of the protein encoded by $c d s-5$ as CDS was provided by expression in COS cells. This required modification of the $c d s-5 \mathrm{pBK}-\mathrm{CMV}$ plasmid for removal of a stop codon in the $5^{\prime}$-untranslated region. CDS activity in COS cells transiently transfected with the modified $c d s$ 5 plasmid showed a mean increase of 4.3-fold (range, 2.84.8-fold) over control COS cells (control vs. transfected, $0.17 \pm 0.04$ vs. $0.73 \pm 0.10 \mathrm{nmol} / \mathrm{min} / \mathrm{mg}$ of protein; $\mathrm{n}=7$; $p<0.001)$. Attempts at $\mathrm{Ni}^{2+}$ affinity purification of the His $_{6}$-tagged protein have thus far been unsuccessful owing to the inability to retain activity of the detergent-solubilized enzyme. The distribution and size of CDS mRNA in human tissues were determined by northern analysis (Fig. 2). A band of $\sim 5 \mathrm{~kb}$ was present in all human tissues examined and was particularly prominent in heart and liver. An additional band of $3 \mathrm{~kb}$ was present in heart and pancreas. At this point it is unclear whether the two mRNAs may represent alternatively spliced forms. Reprobing with an upstream 360-bp fragment gave the same pattern (data not shown).

The $c d s-5$ cDNA thus appears to encode a ubiquitously expressed protein that expresses CDS activity. The possibility of the existence of multiple isoforms of the enzyme remains to be explored. Distinctly different properties have been described for mitochondrial and microsomal CDS of rat liver, supporting the hypothesis that these may represent two distinct gene products. In the yeast, the $C D S 1$ gene was found to encode $>90 \%$ of CDS activity, and null mutants were nonviable (Shen et al., 1996). In the Drosophila study, preliminary results suggested the presence of alternatively spliced CDS isoforms (Wu et al., 1995). The fact that Drosophila CDS mutants are viable and show no defect other than in photoreceptors points to the existence of other CDS 
isoforms for the supply of phosphoinositide precursor in those mutants. The Drosophila eye CDS appears to be specialized for the phototransduction process, and the consequences of alterations in its expression identify it as a key enzyme in the phospholipase $\mathrm{C}$ signaling pathway. Given the multitude of phosphoinositide-linked receptors in neural tissue and the importance of this pathway in neuronal signaling, it is tempting to speculate that such a central role may pertain also to neuronal CDS. The cloning of a vertebrate CDS will facilitate understanding of its regulation, which may, in addition, have implications for the growth factorlinked PI-3-kinase pathway (Kapeller and Cantley, 1994), for PI-anchored proteins (Low and Saltiel, 1988), cytoskeletal modulation (Janmey, 1994), and membrane trafficking (De Camilli et al., 1996).

Note added in proof: The sequence reported in this article has been deposited in the GenBank data base (accession no. U65887).

Acknowledgment: This work was supported by grant $\mathrm{MH}$ 42652 from the National Institute of Mental Health. The expert technical assistance of Edward B. Seguin and secretarial skills of Jo Ann Kelsch are gratefully acknowledged.

\section{REFERENCES}

Agranoff B. W., Bradley R. M., and Brady R. O. (1958) The enzymatic synthesis of inositol phosphatide. J. Biol. Chem. 233, $1077-1083$.

Bradford M. M. (1976) A rapid and sensitive method for the quantitation of microgram quantities of protein utilizing the principle of protein-dye binding. Anal. Biochem. 72, 248-254.

De Camilli P., Emr S. D., McPherson P. S., and Novick P. (1996) Phosphoinositides as regulators in membrane traffic. Science 271, $1533-1539$.

Fisher S. K. and Agranoff B. W. (1980) Calcium and the muscarinic synaptosomal phospholipid labeling effect. J. Neurochem. 34, $1231-1240$.

Fisher S. K., Heacock A. M., and Agranoff B. W. (1992) Inositol lipids and signal transduction in the nervous system: an update. J. Neurochem. 58, 18-38.

Heacock A. M., Uhler M. D., and Agranoff B. W. (1996) Cloning of a human neuronal CDP-diacylglycerol synthase. (Abstr.) $J$. Neurochem. 66 (Suppl. 1), S46D.

Icho T., Sparrow C. P., and Raetz C. R. H. ( 1985) Molecular cloning and sequencing of the gene for CDP-diglyceride synthetase of Escherichia coli. J. Biol. Chem. 260, 12078-12083.

Janmey P. A. (1994) Phosphoinositides and calcium as regulators of cellular actin assembly and disassembly. Annu. Rev. Physiol. 56, 169-191.

Kapeller R. and Cantley L. C. (1994) Phosphatidylinositol 3-kinase. Bioessays 16, 565-576.

Kelley M. J. and Carman G. M. (1987) Purification and characterization of CDP-diacylglycerol synthase from Saccharomyces cerevisiae. J. Biol. Chem. 262, 14563-14570.

Kent C. (1995) Eukaryotic phospholipid biosynthesis. Annu. Rev. Biochem. 64, 315-343.

Kozak M. (1991) Structural features in eukaryotic mRNAs that modulate the initation of translation. J. Biol. Chem. 266, 19867-19870.

Kyte J. and Doolittle R. F. (1982) A simple method for displaying the hydropathic character of a protein. J. Mol. Biol. 157, $105-$ 132.

Langley K. E. and Kennedy E. P. (1978) Partial purification and properties of CTP:phosphatidic acid cytidylyltransferase from membranes of Escherichia coli. J. Bacteriol. 136, 85-95.

Low M. G. and Saltiel A. R. (1988) Structural and functional roles of glycosyl-phosphatidylinositol in membranes. Science 239, $268-275$.

Mok A. Y. P., McDougall G. E., and McMurray W. C. ( 1992) CDPdiacylglycerol synthesis in rat liver mitochondria. FEBS Lett. 312, 236-240.

Shen H., Heacock P. N., Clancey C. J., and Dowhan W. (1996) The CDS1 gene encoding CDP-diacylglycerol synthase in Saccharomyces cerevisiae is essential for cell growth. J. Biol. Chem. 271, 789-795.

Sparrow C. P. and Raetz C. R. H. (1985) Purification and properties of the membrane-bound CDP-diglyceride synthetase from $E s c h$ erichia coli. J. Biol. Chem. 260, 12084-12091.

Thompson W. and MacDonald G. (1976) Cytidine diphosphate diglyceride of bovine brain. Eur. J. Biochem. 63, 107-111.

Wu L., Niemeyer B., Colley N., Socolich M., and Zuker C. S. (1995) Regulation of PLC-mediated signalling in vivo by CDPdiacylglycerol synthase. Nature 373, 216-222. 